\title{
THE CALIBRATION AND USE OF PRESSURE TRANSDUCERS IN TENSIOMETER SYSTEMS
}

\author{
JAMES R. HOELSCHER*, WILLIAM K. NUTTLE†, AND JUDSON W. HARVEY \\ Department of Environmental Sciences, Clark Hall, University of Virginia, Charlottesville, VA 22903, USA
}

\begin{abstract}
The uncertainty in a transducer/tensiometer system was assessed with temperature and pressure calibrations. A reference transducer/tensiometer pair was used to factor out temperature related deviations from two monitoring pairs. The reference pair removed most of the deviations, resulting in a high estimate of precision. In contrast to earlier reports of high accuracy, these estimates of accuracy were considerably reduced by a time correlated residual pattern. The calibrations suggested that the electronic components may be responsible for these residual errors and illustrated the need for experimentation which isolates the error among groups of components. The complexity of transducer/ tensiometer networks, and the differing response of each component to thermal loading, demonstrated the necessity of using a reference system, which when properly designed can yield reliable pressure readings for soil water.
\end{abstract}

KEY WORDS Pressure transducers Tensiometers Mean-squared error Calibration

\section{INTRODUCTION}

Pressure transducers are widely used in soil hydrology investigations (Fitzsimmons et al., 1972; Anderson and Burt, 1978; Marthaler et al., 1983; MacVicar and Walter, 1984; Hoover, 1987) and are generally accepted as the most effective and efficient means of measuring soil water potentials. Although highly accurate readings are achievable in transducer/tensiometer applications (Rice, 1975; Long and Huck, 1980), several investigations have shown the sensitivity of these systems to thermal loadings, resulting in potentially large deviations in the millivolt output (Watson and Jackson, 1967; Trotter, 1984). However, very few field applications have evaluated the sources of uncertainty in their systems (Lowery et al., 1986). Furthermore, the contribution of errors from the electronics to the output signal is largely unexplored in these applications.

A report by Dowd and Williams (1989) examined the errors in a transducer/tensiometer installation. They were able to remove nearly all temperature related deviations in their monitoring instruments with a reference transducer/tensiometer pair. Under moderately high suctions $(1.6 \mathrm{~m})$ and relatively low temperatures $\left(-5\right.$ to $\left.15^{\circ} \mathrm{C}\right)$ in a forest setting, the overall system error was reduced to $1 \mathrm{~cm}\left(\mathrm{H}_{2} \mathrm{O}\right)$.

In a similar fashion, we conducted temperature and pressure calibrations for a transducer/tensiometer system in a tidal marsh environment during the summer of 1989. Three transducer/tensiometer pairs were used, one of which served as a reference for removing temperature related biases in the millivolt output from the two monitoring pairs. Based on our calibrations, we were unable to achieve a level of uncertainty as low as that of Dowd and Williams (1989).

\footnotetext{
* Present address: United States Environmental Protection Agency, Region V, Waste Management Division, Office of RCRA, Indiana Section, 77 W. Jackson Blvd, Chicago, IL 60604, USA.

† Present address: Rawson Academy of Aquatic Science, Suite 404, 1 Nicholas Street, Ottawa, Ontario, Canada K1N 7B7.

† Present address: United States Geological Survey, Water Resource Division, Mail Stop 496, 345 Middlefield Road, Menlo Park, CA 94025 , USA.
} 
Overall, we were pleased with the performance of our system, and the utility of including a reference pair in the experimental design. The unacceptably high levels of uncertainty revealed, however, that inherent sensitivities in the system are magnified under greater thermal loadings (and lower pressures), and that the electronic components in the system may contribute more errors than is often assumed. Although the effects of temperature on individual components are well known, our results illustrated that additional experiments should be undertaken to partition the error between the major groups of components in the system.

\section{INSTRUMENTATION AND FIELD SETTING}

We selected a Druck (the use of trade names does not imply product endorsement by the authors) differential pressure transducer (Type PDCR 10/2L) to monitor pressure in a Soilmoisture tensiometer (Model 2170). The transducers were equipped with temperature compensation electronics to correct the output $( \pm 0.5 \%$ total temperature error over $0-56^{\circ} \mathrm{C}$ ) with negligible hysteresis effects (Druck, 1989). Water pressures were transmitted to the transducers through air filled flexible plastic tubes (Figure 1). All three tensiometers and the associated hardware were identical in design and dimensions. The transducers were mounted in a rain tight enclosure with a Campbell $21 \times$ data logger to ensure that all the electronic components operated at the same temperature. The data logger was programmed to record the millivolt output from the transducers, ambient air and panel temperature, and the relative humidity. In the field, one transducer/tensiometer pair was maintained under constant hydrostatic pressure to serve as a reference for removing temperature related deviations in millivolt output from the 'installed' pairs (Figure 1).

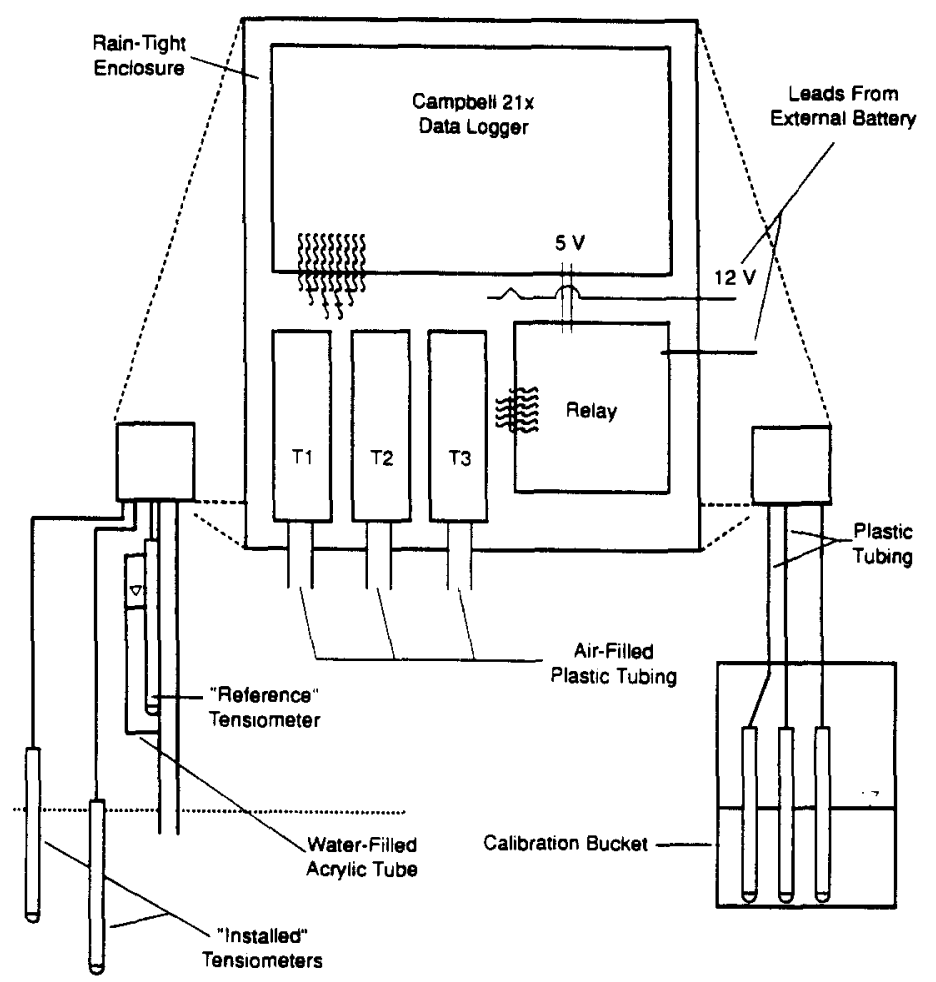

A

B

Figure 1. Schematic diagram of (A) the field set-up and (B) the calibration set-up. The rain tight enclosure containing pressure transducers $\mathrm{T} 1, \mathrm{~T} 2$ and $\mathrm{T} 3$ and associated hardware is detailed in the exploded view 
In our experimental setting - a salt water marsh in Virginia - the soils were nearly saturated, with pore water pressures ranging from -50 to $100 \mathrm{~cm}\left(\mathrm{H}_{2} \mathrm{O}\right)$. Based on these relatively low pressure maxima and minima, and daily water level fluctuations of $10-20 \mathrm{~cm}$, we estimated that the system error should not exceed $\pm 5 \mathrm{~cm}\left(\mathrm{H}_{2} \mathrm{O}\right)$.

\section{CALIBRATION}

We conducted a two step calibration on all transducer/tensiometer pairs, first against pressure at a constant temperature and then against temperature at a constant pressure. Millivolt output-pressure relationships were derived from experiments undertaken in a laboratory in which the temperatures remained nearly constant $\left( \pm 1^{\circ} \mathrm{C}\right)$ over the course of the calibration. For each pair, output millivolt values were regressed on observed water pressure. The relationship between millivolt output and water pressure were similar for all pairs. The output precision (with respect to pressure) was estimated with the mean squared error (MSE), which represents the average deviation of the observed from the predicted millivolt output. For each transducer, the MSE was estimated to be $0.088 \mathrm{mV}$, or $0.9 \mathrm{~cm}\left(\mathrm{H}_{2} \mathrm{O}\right)$ with the greatest deviation between observed and predicted output being $0.15 \mathrm{mV}$.

We examined output deviations due to environmental factors by conducting temperature calibrations in the field. Before the installation of the system, all three tensiometers were placed in a bucket filled with tap water with a water level exerting a near atmospheric pressure $(+5 \mathrm{~cm})$ on the transducers (Figure 1). This pressure was used because it approximated the average anticipated soil water pressure in the marsh soils. To minimize the potential for differential responses due to tensiometer attributes, the air 'head space' above the column of water within each tensiometer was relatively small and roughly equal in all instruments.

\section{RESULTS}

During the temperature calibrations, all output signals varied by approximately $1.5 \mathrm{mV}$ (Figure 2 ), or $15 \mathrm{~cm}\left(\mathrm{H}_{2} \mathrm{O}\right)$ over a fairly narrow range of temperatures $\left(15^{\circ} \mathrm{C}\right)$. Opposing trends in output were observed during a long cooling period after midnight on day 251 (Figure 2); the output trace from the 'reference' pair continued to decrease with temperature, whereas readings from the two 'installed' pairs began to increase (Figure 2).

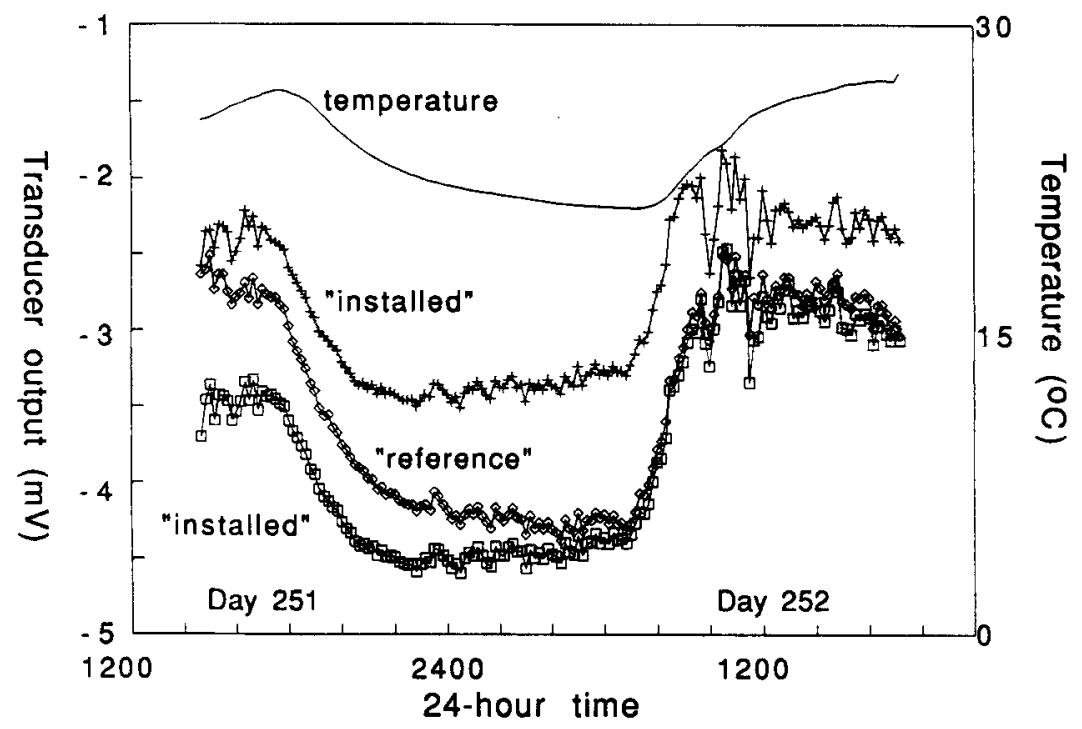

Figure 2. Millivolt output from all transducers and temperature recordings observed during two day temperature calibrations. Major temperature related deviations in the output are evident 
To remove the major temperature trend deviation in the recordings from the 'installed' pairs, we explored several correction techniques which used the reference recording as the independent variable. We determined that regression on the reference output yielded the lowest MSE $\left[0.25 \mathrm{mV}, 2.5 \mathrm{~cm}\left(\mathrm{H}_{2} \mathrm{O}\right)\right]$. Suggesting a rather high degree of precision, this value reflected the clustering of data points at either end of the 'installed' reference ellipsoid (Figure 3). At the sampling times represented by the ellipsoid ends, the responses between the reference and installed pairs diverged, with a considerable lag that resulted in a distinct grouping of data points.

Although we achieved a high degree of precision with this correction technique, it (and other linear methods we tested) could not remove hysteretic temperature effects and differential transducer responses to temperature, both of which considerably reduced the accuracy of the output millivolt readings. The accuracy of the 'installed' signals was assessed by plotting the regression residuals on 'reference' output (Figure 4).

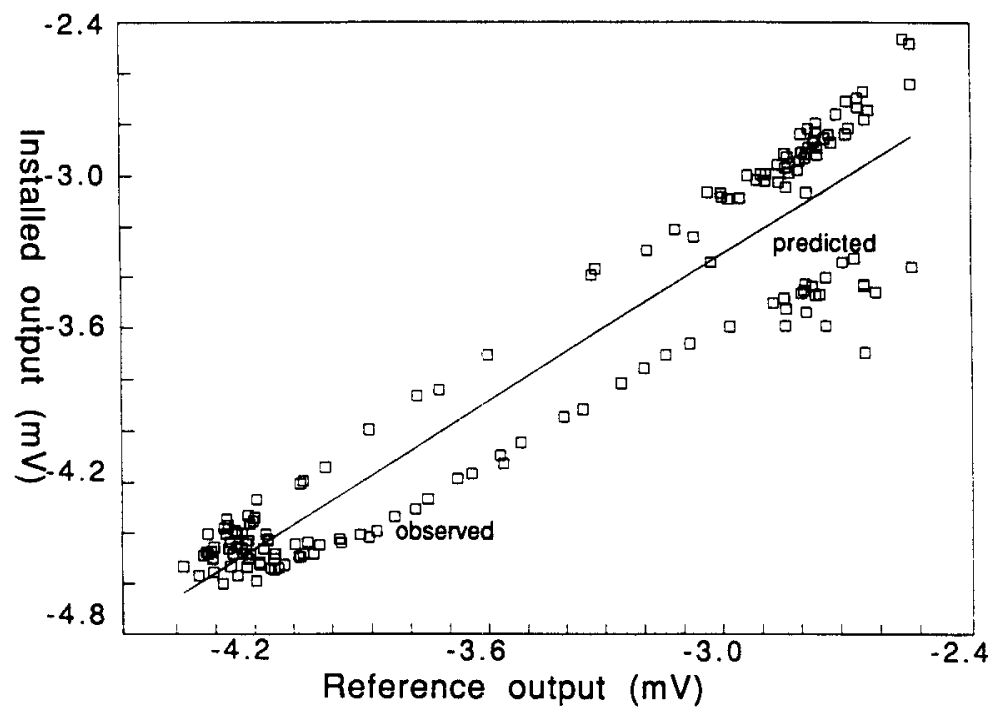

Figure 3. Relationship between the millivolt output from an 'installed' transducer and the 'reference' transducer output with corresponding regression line. Regression on the 'reference' output removed the major temperature related trends in the output from the 'installed' pairs

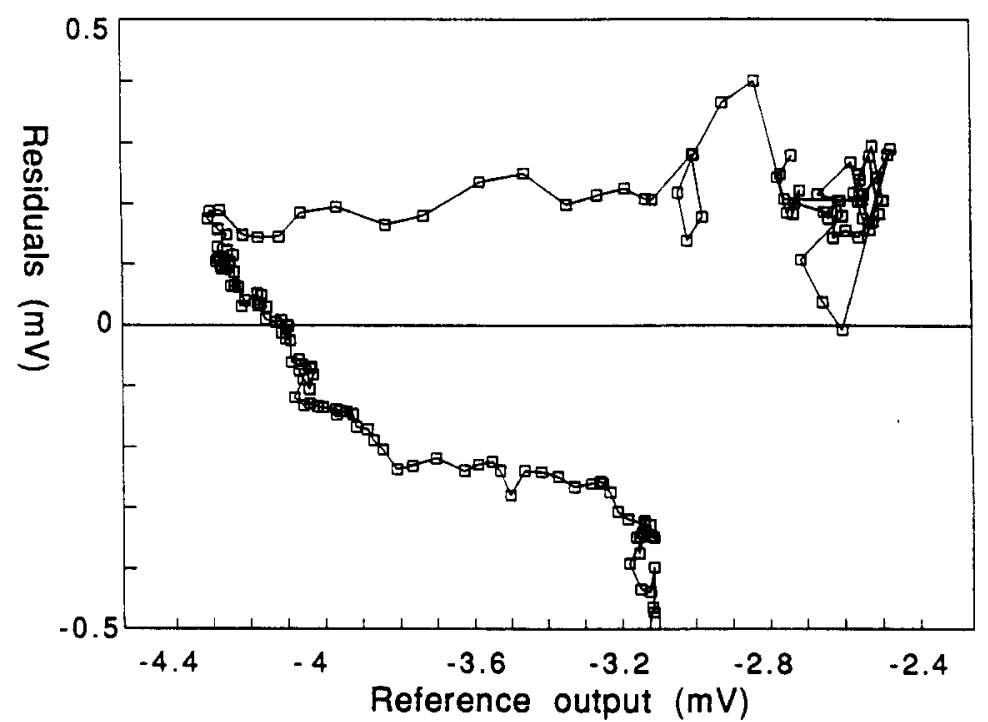

Figure 4. Accuracy of the system with respect to temperature estimated by plotting the millivolt output residuals from 'installed' pairs against 'reference' transducer output. This markedly non-random pattern provided an accuracy estimate of $\pm 0.5 \mathrm{mV}$ 
A high accuracy would be represented by a random scattering of residuals clustered along the 'zero value' residual line. However, the residuals were highly correlated in time, and arranged in a markedly non-random pattern, which may have resulted from differential responses with the reference transducer (Figure 4). Clearly, the accuracy of the output values is linked to the residual pattern because at any measurement interval the closeness of the millivolt output to the 'actual' value would be controlled by the most recent temperature cycle and the response time lag between transducers. The most representative estimate of the output accuracy should be the range subtended by the residuals above and below the 'zero value' residual line. This method provided an estimate of $\pm 0.5 \mathrm{mV}$, or $\pm 5 \mathrm{~cm}\left(\mathrm{H}_{2} \mathrm{O}\right)$.

Owing to the short duration of our field season, we were not able to evaluate long term drift errors. We assumed that the regression relationships for removing temperature bias were stationary, and hence we cannot estimate the total uncertainty in the pressure measurements over our study period.

\section{DISCUSSION}

It has been recognized for some time that tensiometer systems are sensitive to thermal loading (Watson and Jackson, 1967; Schuster, 1974). In our system, the large excursions in millivolt output observed during temperature calibrations (Figure 2) represent the net effect of thermal loading on all components, electrical and mechanical. These two groups of components respond to temperature differently: the first produces an actual pressure deviation due to the heating or contraction of the material, water and air in the system (Lowery et al., 1986). This pressure deviation is eventually relieved through the ceramic cup as the system equilibrates back to the potential of the surrounding soil. The response of the electrical components, however, is less straightforward and produces a deviation that cannot be easily reasoned out or removed. Although much smaller, this error is often overlooked in system calibrations.

Ideally, it is reasonable to assume that three transducer/tensiometer pairs which share identical components, installation, dimensions and thermal loadings (as was the case in this temperature calibration) should yield nearly identical output signals. With a reference pair, the patterns of the residuals from the 'installed' pairs would centre closely to zero over time. In this system, however, any number of variables may have been responsible for the excessively large residual deviations (Figure 4). We believe that the source of this error may lie, in part, with the electronics.

In previous investigations, we have observed that each data logger channel behaves slightly differently. The calibration equation for a given transducer/tensiometer pair changes with each channel selected. The degree to which these differences change as a function of temperature is not certain, but each channel and associated hardware may respond differently to temperature changes. These factors would result in a slight offset among channel-transducer pairs. Our interpretation of the residual error is also based on the presupposition that minor variations in the material and dimensions of the physical components among each pair would not produce a residual error of the magnitude observed in this system.

In all likelihood, the source of the residual error is related to the interaction of several components. We emphasize the electronics because they are often assumed to contribute negligible errors to the system, and given the design of a reference system they are a critical component of the errors in the system. A consideration of their interaction with other parts of the system may assist in designing a more effective correction technique. Although we cannot fully partition the uncertainty among all the components, the motivation for doing so serves to illustrate the complexity of these systems.

We believed that the reference pair would eliminate sufficient uncertainty in the data to examine potential changes of the order of $5 \mathrm{~cm}$. We did not meet this target level of uncertainty, but reduced it to a level which may be acceptable in other field investigations. Several other routes may be explored to further reduce the error, the most apparent of which is to examine the effect of thermal loading on each individual component. As a result of the interaction among all components, however, we would not recommend this approach.

In theory, a series of experiments could be designed to isolate the main effects of thermal loading on each component in this transducer/tensiometer system. Clearly, each component responds differently to thermal loading, and it is evident that certain components (particularly mechanical components such as the air filled lines) would be much more temperature sensitive than others (for example, the ceramic cup). It is important 
to remember, however, that each component's response is in turn dependent on the behaviour of the other components. Furthermore, it is probable that the interaction between components under different thermal and pressure regimes would render any corrective model (one built from the response of each component) obsolete. In such a highly complicated system, a reference pair represents the easiest and most efficient means of reducing errors.

The most enlightening series of experiments would focus on distinguishing between electrically based and actual pressure deviations. We would recommend an approach similar to ours [and that of Dowd and Williams (1989)] with a reference pair and corresponding corrective model. A three variable experiment which considered the physical components, the transducers and the data logger channels (each group as a variable) would clarify the error contribution from each group of components. All possible combinations of data logger channel, transducer and tensiometer would be loaded under identical thermal conditions. By evaluating the response of each combination of component groups, the source of the residual error could be reduced and more conclusively attributed to one of the groups.

Our results also confirm the long-recognized observation that thermal loading on the monitoring system should be minimized as much as possible. Our research setting is probably a 'worst case' scenario because of its minor and near atmospheric water level fluctuations and its marked temperature excursions. The work of Dowd and Williams (1989) shows the high level of precision and accuracy that can be achieved when thermal loadings (both direct solar and temperature) are relatively modest. Furthermore, the applied pressure may have had a dampening effect on the sensitivity of their transducers to temperature fluctuations (Trotter, 1984). Our experiments were conducted under near atmospheric potentials, whereas considerable suction $(1.6 \mathrm{~m})$ was exerted on their transducers. It is clear, however, that in a setting such as ours, a reference pair system should be supplemented with a fairly comprehensive shielding layout. If such a system were implemented in our study, we would expect our residual errors to be lower.

\section{CONCLUSIONS}

Our results have shown that low levels of uncertainty can be achieved with a reference transducer/ tensiometer system when it is designed correctly. Although we have implied that transducers and data loggers may be responsible for our residual error, we recommend experiments designed to clarify the error contribution of each by grouping the deviations between those two variables and the physical components.

Unfortunately, the level of uncertainty in our data was unacceptably high, although it would probably be acceptable in longer time scale experiments where high resolution is not required. Our equipment and experimental design were essentially identical to those used by Dowd and Williams (1989), who reported uncertainty levels considerably lower than ours. Our research setting magnified the errors present in their system. The use of a reference system does not relieve the researcher of the need to minimize thermal loadings on the system, and may leave unacceptable levels of uncertainty in the data. However, a transducer/ tensiometer system with a reference, combined with proper shielding, represents the most efficient means of making reliable water potential measurements in soils.

\section{ACKNOWLEDGEMENTS}

This work was supported in part by NSF grant BSR-8702333 to the University of Virginia, and is a contribution to the Virginia Coast Reserve Long-term Ecological Research Program. The authors thank Ann Rintz for her professional drafting skills on the schematic drawing.

\section{REFERENCES}

Anderson, M. G. and Burt, T. P. 1978. 'Automatic monitoring of soil moisture conditions in a hillslope spur and hollow', J. Hydrol., 33, 27-36.

Dowd, J. F. and Williams, A. G. 1989. 'Calibration and use of pressure transducers in soil hydrology', Hydrol. Process. 3, 43-49.

Druck Incorporated 1989. Technical Reference Sheet \# PDCR 10/L, Druck Inc. 
Fitzsimmons, D. W. and Young, N. C. 1972. 'Tensiometer-pressure transducer system for studying unsteady flow through soils', Transactions of the American Society of Agricultural Engineers, 15, 272-275.

Hoover, J. R. 1987. 'Instrumentation system for determining watershed hydrologic characteristics', T ASAE, 30, $1051-1056$.

Long, F. L. and Huck, M. G. 1980. 'An automated system for measuring soil water potential gardients in a rhizotron soil profile', Soil Sci. 129, 305-310.

Lowery, B., Datiri, B. C., and Andraski, B. J. 1986. 'A new solid-state device for automatically measuring soil water potential', Soil Sci. Am. J., 50, 494-496.

MacVicar, T. K. and Walter, M. F. 1984. 'An electronic transducer for continuous water level monitoring', Transactions of the American Society of Agricultural Engineers, 27, 105-109.

Marthaler, H. P., Vogelsanger, W., Richard, F., and Wierenga, P. F. 1983. 'A pressure transducer for field tensiometers', Soil Sci. Am. J., 47, 624-627.

Rice, R. C. 1975. 'Diurnal and seasonal soil water uptake and flux within a bermuda grass root zone', Soil Sci. Am. Proc., 39, 394-398.

Schuster, C. 1974. 'Wasserspiegelabsenkung zwischen zwei Drainagegraben in naturlich gelagertem Boden am Hang', Mitteilungen der Eidgenossichen Anbstalt für das forstliche Versuchswesen, 50, 5-83.

Trotter, C. M. 1984. 'Errors in reading tensiometer vacua with pressure transducers', Soil Sci., 138, 314-316.

Watson, K. K. and Jackson, R. D. 1967. 'Temperature effects in a tensiometer-pressure transducer system', Soil Sci. Am. Proc., 31, $156-160$. 